\title{
REPRESENTAÇÕES SOCIAIS SOBRE ADOÇÃO DE CRIANÇAS E ADOLESCENTES INSTITUCIONÁLIZADOS: UM ESTUDO ENTRE UNIVERSITÁRIOS DE PSICOLOGIA E DIREITO
}

\author{
Ana Maria Justo ${ }^{1}$ \\ Luisa Carina Gessi Rippel ${ }^{2}$ \\ Tamara Conte Maier ${ }^{3}$
}

Resumo. O presente estudo visa analisar as representações sociais da adoção de crianças e adolescentes institucionalizados para estudantes de psicologia e direito. Os dados foram obtidos através da aplicação de questionários, com questões abertas e fechadas, incluindo um teste de evocações livre. A análise envolveu estatística descritiva, análise lexicográfica e análise de conteúdo temático-categorial. Participaram 200 estudantes universitários, sendo 100 estudantes do curso de psicologia e 100 estudantes do curso de direito, de uma universidade do sul do país. Constata-se que os elementos centrais são compartilhados pelos estudantes e pautam a adoção na ideia de afeto e família. Os elementos da periferia da RS indicam diferenças sutis entre os grupos, sendo que os estudantes de direito evocaram elementos mais pragmáticos e os de psicologia são mais favoráveis à adoção. Ainda se verifica uma representação estereotipada da adoção entre os futuros profissionais, sendo necessária a realização de mais estudos na área, assim como maior abordagem do tema nos cursos de graduação.

Palavras-chave: Representações sociais; Adoção; Estudantes.

\section{SOCIAL REPRESENTATIONS ON ADOPTION OF INSTITUTIONALIZED CHILDREN AND ADOLESCENTS: A STUDY BETWEEN UNIVERSITARIANS OF PSYCHOLOGY AND LAW}

\begin{abstract}
The present study aims to analyze the social representations of the adoption of institutionalized children and adolescents for students of psychology and law. Data were obtained through the application of questionnaires, with open and closed questions, including a free evocation test. The analysis involved descriptive statistics, lexicographic analysis and content analysis. 200 university students participated, including 100 undergraduate psychology students and 100 law students from a university in the south of Brazil. We noted that the central core elements are shared by the students and they hold the adoption representation in the idea of affection and

\footnotetext{
${ }^{1}$ Doutora em Psicologia pela Universidade Federal de Santa Catarina. Professora Adjunta do Departamento de Psicologia Social e do Desenvolvimento da Universidade Federal do Espírito Santo - Email: justoanamaria@gmail.com

${ }^{2}$ Psicóloga e Pós-Graduanda em Saúde Mental e Atenção Psicosssocial, pela UNIDAVI - E-mail: luisa_rippel@hotmail.com

${ }^{3}$ Psicóloga graduada pela UNIDAVI - E-mail: tamyconte@ hotmail.com
} 
family. The peripheric elements of the RS indicate subtle differences between groups, with law students evoking more pragmatic elements and psychology students are more favorable to adoption. There is still a stereotyped representation of the adoption among the future professionals, being necessary the accomplishment of more studies in the area, as well as greater approach of the subject in the undergraduate courses.

Keywords: Social representations; Adoption; Students.

\section{Introdução}

O conceito e os objetivos da adoção têm mudado ao longo dos anos, trazendo reflexões quanto a esta prática social. Atualmente, as concepções sobre adoção, passam pelo campo jurídico, psicológico, social e histórico, e a adoção pode ser determinada como obtenção de filhos através da Lei, sempre privilegiando as necessidades e direitos básicos da criança e adolescente, permitindo a estes o direito de crescer e ser educado em uma família. Mas nem sempre fora assim. Outrora realizada para suprir os desejos de casais que não podiam conceber filhos biológicos, hoje concebe as crianças e adolescentes como os protagonistas do processo (WEBER, 2004). Muitas transformações sociais, jurídicas e psicológicas ocorreram ao longo da história e das diferentes culturas para que esta prática se tornasse valorizada e de interesse da sociedade.

Weber (1999) aponta que se deve entender a adoção como um tipo de parentalidade e filiação igualmente importante e com a mesma essência que uma família que tenha filhos biológicos. Conforme Trindade (2010), a adoção é uma forma de inserir a criança ou adolescente em uma família disposta a dar-lhe amor, e atenção, garantindo seu desenvolvimento; e é considerada uma forma de recriar vínculos significativos entre esta nova família.

Desde a antiguidade, em diferentes culturas, convive-se com práticas de adoção por meio de diferentes formas de inserção de crianças em lares e famílias substitutas. Para a cultura grega, a adoção era resultado de necessidades jurídicas e religiosas, pois a família e os costumes não poderiam ser extintos, sendo possível adotar um estranho, para quem a herança pudesse ser deixada. Já na Idade Média, a Igreja não via com muito agrado a instituição da adoção, pois a mesma feria os preceitos do casamento, já que a adoção estaria "imitando" a natureza. Na Idade Moderna, criou-se um mecanismo 
social, a "Roda dos Enjeitados ou dos Expostos", para solucionar o nascimento de uma criança ilegítima, pois esta era reprovada pela sociedade. No Brasil, este mecanismo existiu por longo período, sendo um dos últimos países a acabar com a prática de abandono anônimo de crianças (WEBER, 2004).

A adoção passa a ter maior importância social após a Primeira Guerra Mundial, quando houve um crescente número de órfãos, e, consequentemente, a legislação passou a ter um olhar sobre os direitos da criança na adoção, quando uma família substituta poderia garantir dignidade e respeito à criança que perdeu seus pais na guerra (WEBER, 2004). Nessa época, a adoção vem a ser valorizada, para homenagear os pais considerados heróis, que morreram durante este período (CAMARGO, 2005).

No Brasil, a adoção teve influência do Reino de Portugal, sendo incluída no Código Civil em 1916 (MONACO, 2002). Ao longo dos anos, diversas leis foram criadas para que esta prática se tornasse acessível à população, e para que muitas crianças ou adolescentes fossem colocadas em uma família.

Tendo como base a Declaração Universal de Direitos da Criança, de 1959, e juntamente com os movimentos sociais da época, foi criado o Estatuto da Criança e do Adolescente (ECA), Lei de $n^{\circ}$ 8.069, de 1990. A adoção surgiu do artigo 227 da Constituição Federal, e a sua criação foi essencial para o avanço no processo de adoção, onde os filhos adotados passam e ter os mesmos direitos que os filhos biológicos. De acordo com o ECA a adoção deve se dar por amor, oferecendo desenvolvimento, saúde, educação, contato social, e estando inserido em uma família que possa garantir seus direitos e cumprir seu dever social. (CAMARGO, 2005). Somente a partir do ECA (1990), que os direitos da criança e do adolescente passaram a ser valorizados no processo de adoção. Sendo que ele defende que "toda criança ou adolescente tem direito a ser criado e educado no seio da sua família, podendo ser em família substituta, que assegurará convivência familiar”. As crianças ou adolescentes, terão os mesmos direitos e qualificações que um filho biológico, pois se atribuiu na adoção a condição de filho e de pais.

Em 2009 entrou em vigor a Lei de ${ }^{\circ}$ 12.010/2009, que é disciplinada pelo ECA e traz uma visão ampliada para o termo família. Foi criado o Cadastro Nacional de Adoção, para pessoas que tem interesse em adotar, onde os pretendentes a adoção são 
avaliados e aguardam pela concretização da adoção, sendo que esta medida, tem a intenção de impedir a adoção direta, ou ilegal (TRINDADE, 2010).

A prática da adoção é realizada por uma equipe multiprofissional, que compartilha conhecimentos com outras áreas sobre o assunto. O psicólogo está inserido em processos que envolvem a adoção, desde a habilitação dos candidatos, o preparo e apoio psicológico e o posterior acompanhamento das famílias. Nesse sentido, evidenciase a importância das ações compartilhadas entre profissionais da área da psicologia e do direito, configurando a adoção como um campo de intervenção interdisciplinar.

Conforme abordado, a adoção trata-se de um fenômeno social, que historicamente tem implicações tanto no que se refere à família e ao desenvolvimento da criança ou adolescente, quanto no que diz respeito a normas e estruturas sociais. Nesse sentido, destaca-se que a adoção pode ser um objeto pertinente ao estudo de representações sociais (RS).

Segundo Vala (2006), a teoria das representações sociais consiste numa teoria científica sobre os processos por meio dos quais os indivíduos em interação social constroem explicações acerca dos objetos sociais. As RS, também chamadas de pensamento do senso comum, são formadas para tornar familiar o incomum, permitindo que se dê sentido aos fatos novos ou desconhecidos, tornando acessível o inacessível. Moscovici elaborou a teoria das RS na tentativa de explicar o comportamento da sociedade contemporânea, ligada a processos de comunicação e informação social; uma vez que é a comunicação com as outras pessoas que possibilita o conhecimento social, a partir dos pensamentos que os indivíduos compartilham sobre o seu mundo (JODELET, 2001; PALMONARI \& CERRATO, 2011; WACHELKE, 2012).

Moscovici (1981) salienta que se deve entender a RS como um conjunto de imagens, afirmações e explicações originadas no cotidiano no decurso de comunicações interindividuais. Jodelet (2001) afirma a importância das RS na vida das pessoas, pela sua interferência nas interações sociais e na produção de sentidos coletivos, por guiar e definir os aspectos da realidade, interpretando-os, para se chegar a uma tomada de decisão e de posicionamento frente aos objetos. Santos e Almeida (2005) consideram que a partir das representações é possível compreender e explicar a construção do conhecimento do senso comum, com a função de produzir a realidade para o grupo, 
organizar as comunicações, orientar as condutas, definir a identidade pessoal e expressão do grupo, de maneira ativa nas transformações sociais.

A RS se organiza em torno de dois subsistemas: um núcleo central e um sistema periférico, sendo que tal organização permite a atualização e ao mesmo tempo a sua manutenção (RATEAU, 2004). O núcleo central é constituído de um ou alguns elementos, mas sempre em quantidade limitada, que determinam tanto o significado da representação, a organização interna e a estabilidade das RS, sendo responsável pela existência de um consenso apresentado pelo grupo (ABRIC, 2003; RATEAU, 2004).

O sistema periférico é menos limitante que o núcleo central e a parte mais acessível da representação (ABRIC, 2003); é mais flexível e permite uma postura adaptativa individualizada, sendo responsável pelas diferenças nos pontos de vistas dos indivíduos (RATEAU, 2004). Conforme Abric (2003), o núcleo central constitui a base comum e consensual de uma representação social, e procurar o núcleo central é procurar a raiz, o fundamento social da representação, que em seguida será modulada, diferenciada e individualizada no sistema periférico.

Em síntese, pode-se dizer que a teoria das representações sociais busca conceituar a realidade social e a atuação dos sujeitos, sendo um elo entre o real, psicológico e o social, podendo estabelecer ligações entre a vida abstrata, o saber, as crenças e a vida concreta dos indivíduos. Dessa forma, as representações sociais compreendem a construção de significados sobre o meio social, orienta a conduta dos sujeitos sociais e modela o meio social em que o comportamento é reproduzido (JODELET, 2001; MOSCOVICI, 2012).

O objetivo do presente estudo é o de caracterizar, analisar e comparar as RS sobre adoção de crianças e adolescentes institucionalizados entre estudantes universitários de Psicologia e Direito. Através da descrição da RS da adoção é possível visualizar como determinado grupo concebe essa prática; identificar quais suas influências na vida das pessoas e os fatores que consideram interferir ou dificultar o processo de adoção. Pensando nas RS como guias para ação (JODELET, 2001), tem-se elementos para compreender e intervir nas futuras práticas dos profissionais que atuarão nessa área.

RPI Revista de Pesquisa Interdisciplinar, Cajazeiras, v. 2, n. 2, 172-191, jun/dez. de 2017. 


\section{MÉTODO}

Para estudar as representações sociais da adoção de crianças e adolescentes institucionalizados para estudantes universitários foi realizado um estudo exploratório, descritivo e comparativo (BLOGOSLAWSKI; FACHINI; FAVERI, 2010).

\section{Participantes}

Os participantes da pesquisa foram 200 estudantes universitários do Centro Universitário para o Desenvolvimento do Alto Vale do Itajaí - UNIDAVI, Campus Rio do Sul, sendo 100 acadêmicos do curso de direito e 100 acadêmicos do curso de psicologia. Todos os participantes foram voluntários e assinaram o Termo de Consentimento Livre e Esclarecido - TCLE.

\section{Local}

O local para a realização da coleta de dados foi o Campus da UNIDAVI de Rio do Sul - SC, nas salas de aula dos cursos de psicologia e direito, durante o período noturno.

\section{Aspectos éticos da pesquisa}

O projeto foi submetido ao Comitê de Ética em Pesquisa com seres humanos da universidade, tendo sido aprovado. Em todas as turmas, desde o pré-teste até a aplicação efetiva dos questionários, todos os participantes assinaram o Termo de Consentimento Livre e Esclarecido (TCLE), levando consigo uma cópia do mesmo. Os participantes também tiveram a possibilidade de obterem os resultados da pesquisa.

\section{Instrumento}

RPI Revista de Pesquisa Interdisciplinar, Cajazeiras, v. 2, n. 2, 172-191, jun/dez. de 2017. 
Como instrumento para a pesquisa foi utilizado um questionário com questões abertas e fechadas, contemplando itens relacionados à representação social da adoção de crianças e adolescentes institucionalizados (teste de evocação livre), atitude em relação à adoção, a proximidade dos participantes em relação à mesma e a caracterização sóciocultural dos participantes.

\section{Procedimento de coleta de dados}

Inicialmente foram realizados pré-testes, na intenção de validar o roteiro do questionário. Então foi realizado um primeiro contato com os coordenadores dos cursos de psicologia e direito, e os professores foram consultados previamente para o agendamento da aplicação dos questionários nas salas de aula. A aplicação dos questionários foi realizada de forma coletiva em salas de aula. Os participantes foram informados sobre o sigilo que preserva sua identificação e a participação de todos foi voluntária.

\section{Procedimentos para análise de dados}

Após coletados os dados, as questões foram tabuladas em um banco de dados no software PSSP (Statistical Analysis Software). A análise dos dados envolveu estatística descritiva, para questões fechadas; análise de conteúdo temático-categorial para as questões abertas, conforme descrito por Bardin (1977); e análise lexicográfica para o teste de evocações livres, a qual foi realizada com o auxílio dos softwares EVOCATION 20002000 (VERGÈS, SCANO \& JUNIQUE, 2002) e SIMILITUDE 2000 (VERGÈS, JUNIQUE, BARBRY, SCANO \& ZELIGER, 2002).

\section{RESULTADOS}

\section{Análise de evocações livres dos estudantes de psicologia}

A partir do conteúdo semântico ativado pelo teste de evocação livre entre os estudantes de psicologia, os resultados mostram que foram realizadas 496 evocações, de 124 palavras diferentes. Foram excluídas da análise as palavras que tiveram frequência 
inferior a três, e obteve-se a frequência média das palavras evocadas com valor igual a nove. As palavras com frequência superior a três encontram-se apresentadas na Tabela 1, em função dos critérios de frequência e rang médio (ordem de evocação - OME).

Tabela 1. Evocações a partir do termo indutor "adoção" para estudantes de psicologia.

\begin{tabular}{|c|c|c|c|c|c|c|}
\hline & \multicolumn{3}{|c|}{$\mathrm{OME}<3$} & \multicolumn{3}{|c|}{ OME $>=3$} \\
\hline & Elemento & $F$ & $O M E$ & Elemento & $F$ & $O M E$ \\
\hline \multirow{9}{*}{$f>9$} & Amor* & 59 & 2,32 & Família* & 42 & 3,09 \\
\hline & Criança & 29 & 1,75 & Carinho & 33 & 3,21 \\
\hline & Filhos* & 13 & 1,69 & Lar & 15 & 3,06 \\
\hline & Pais & 10 & 2,5 & Abandono & 13 & 3,07 \\
\hline & Solidariedade* & 10 & 2,1 & Cuidado & 12 & 3,50 \\
\hline & & & & Acolhimento & 10 & 3,10 \\
\hline & & & & Afeto* & 9 & 3,22 \\
\hline & & & & Compaixão & 9 & 3,11 \\
\hline & & & & Responsabilidade & 9 & 3,00 \\
\hline \multirow{11}{*}{$f<9$} & Dificuldade & 5 & 2,8 & Dedicação & 8 & 3,62 \\
\hline & Tristeza & 4 & 2,75 & Felicidade & 8 & 3,37 \\
\hline & Oportunidade & 4 & 2,50 & Esperança & 7 & 3 \\
\hline & Carência & 4 & 2,50 & Ajuda & 5 & 4,2 \\
\hline & Sofrimento & 4 & 2,00 & Burocracia & 6 & 3,16 \\
\hline & Doação & 4 & 2,00 & Preconceito & 5 & 3,40 \\
\hline & & & & Disponibilidade & 4 & 4,25 \\
\hline & & & & Respeito & 5 & 3,00 \\
\hline & & & & Solidão & 4 & 3,50 \\
\hline & & & & Bondade & 4 & 3,50 \\
\hline & & & & Alegria & 4 & 3,50 \\
\hline
\end{tabular}

* Elementos com centralidade confirmada a partir da escolha das duas palavras mais importantes.

Conforme se pode observar na Tabela 1, no primeiro quadrante (superior esquerdo) encontram-se os elementos: amor, criança, filhos, pais e solidariedade. Estes elementos são os que foram evocados nos primeiros lugares e com maior frequência, sugerindo um possível núcleo central à representação (ABRIC, 2003). No teste de centralidade foram confirmados como centrais: amor, filhos, solidariedade, presentes no primeiro quadrante e família e afeto presentes no segundo quadrante. Destaca-se o elemento amor, com frequência consideravelmente superior aos demais, sendo o principal elemento organizador da RS. 
No quadrante superior direito encontram-se os elementos evocados menos prontamente e com frequência superior à média: família, carinho, lar, abandono, cuidado, acolhimento, afeto, compaixão e responsabilidade; os quais, juntamente com os elementos do terceiro quadrante (inferior esquerdo: dificuldade, tristeza, oportunidade, carência, sofrimento, doação, caridade, pena, orfanato) constituem a periferia próxima. Tais elementos objetificam e tornam pragmáticas as normas e valores presentes no núcleo da RS.

Por fim, a periferia longínqua encontra-se no quarto quadrante (inferior direito) e diz respeito às representações individuais ou de subgrupos, aspectos menos compartilhados da RS (WACHELKE \& CAMARGO, 2007), elementos como: dedicação, esperança, ajuda, burocracia, preconceito, solidão e bondade.

O estudo da conexidade dos elementos para os estudantes de psicologia permite visualizar a organização da representação, cujo resultado é ilustrado na árvore máxima, que mostra as relações entre os elementos a partir do filtro de um número mínimo de coocorrências (Figura 1). Realizou-se categorização temática do material para esta análise e resultaram 21 categorias, de modo que 15 delas (cujo número de coocorrências foi superior a 5) estão representadas na árvore da Figura 1.

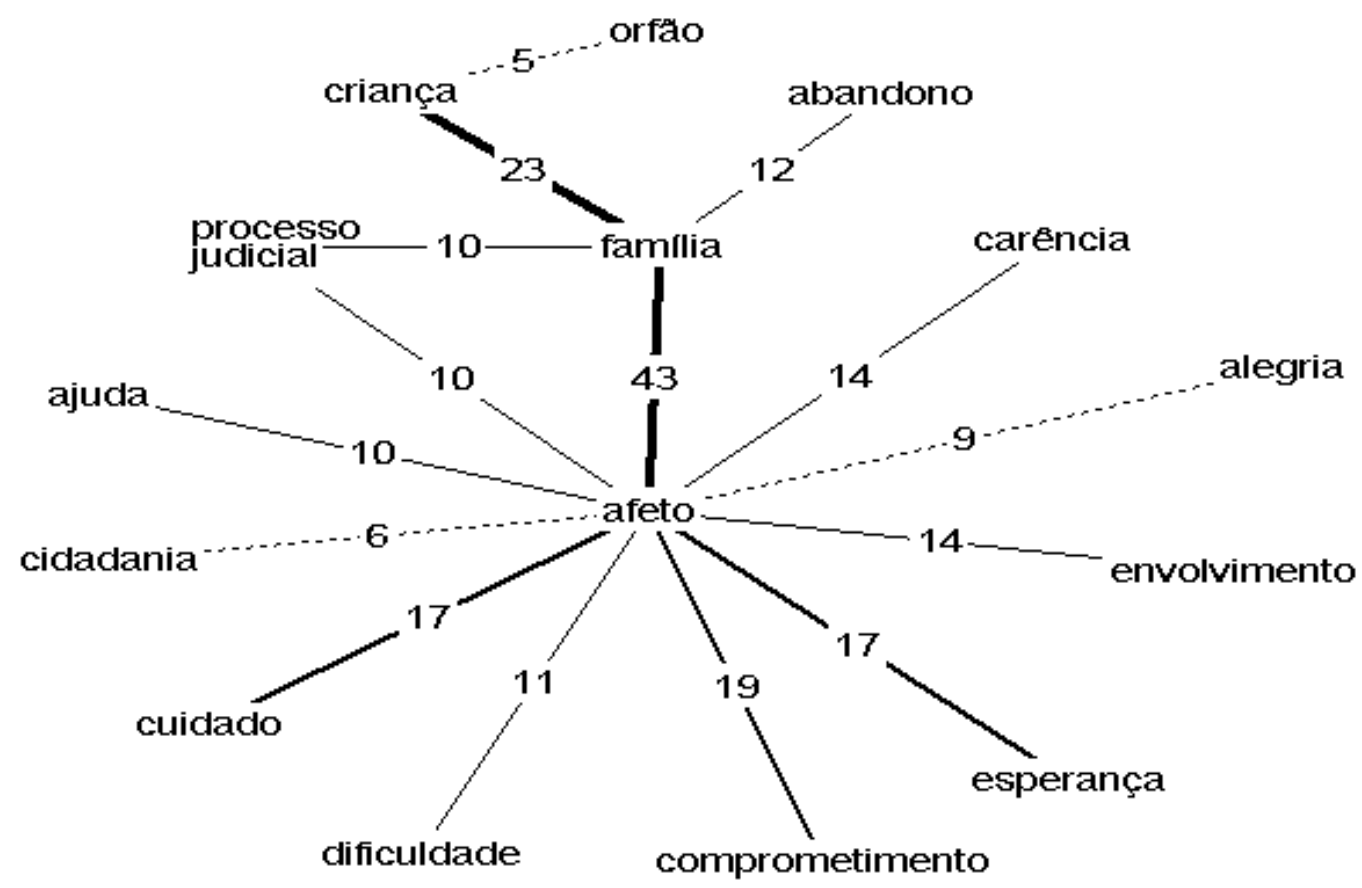

Figura 1. Árvore máxima psicologia com clique 6

RPI Revista de Pesquisa Interdisciplinar, Cajazeiras, v. 2, n. 2, 172-191, jun/dez. de 2017. 
Reitera-se, a partir desta análise, que o elemento na RS da adoção mais compartilhado entre os integrantes do grupo de psicologia é o amor.

Verifica-se maior ligação entre os elementos afeto e família tendo maior número de coocorrências entre eles, sendo estes os elementos centrais, organizadores da representação (ABRIC, 2003). Há também forte coocorrência entre família e criança, que e junto com as demais categorias, dão sentido a representação da adoção. A categoria afeto está ligada a maior parte das categorias, tais como família, comprometimento, cuidado, esperança, carência, envolvimento, dificuldade, ajuda, alegria, cidadania e processo judicial, este último, que está ligado à categoria família. É possível observar a categoria família ligada à categoria criança, que se liga a idéia de crianças órfãs. Também é possível verificar a conexão entre as categorias família e abandono.

\section{Análise de evocações livres estudantes de direito}

Para os estudantes de direito o conteúdo de representações sociais sobre adoção ativadas pelo teste de evocação livre, expressou-se pela emergência de 499 evocações, de 147 palavras diferentes. Foram excluídas da análise as palavras que tiveram frequência inferior a três, e obteve-se a frequência média das palavras evocadas com valor igual a nove. As palavras com frequência superior a três encontram-se apresentadas na Tabela 2, em função dos critérios de frequência e rang médio (Ordem média de evocação - OME).

Conforme se pode observar na Tabela 2, no primeiro quadrante (superior esquerdo) encontram-se os elementos: amor, família, criança, afeto, abandono, solidariedade e filhos. Estes elementos são os que foram evocados nos primeiros lugares e com maior frequência, o teste de centralidade confirmou como elementos centrais da RS: amor, família, afeto, estando no primeiro quadrante e responsabilidade no segundo quadrante. Destaca-se o elemento amor, com frequência consideravelmente superior aos demais, sendo elemento organizador da RS, seguido pelo elemento família que também possui destaque.

RPI Revista de Pesquisa Interdisciplinar, Cajazeiras, v. 2, n. 2, 172-191, jun/dez. de 2017. 
No quadrante superior direito encontram-se os elementos evocados menos prontamente e com frequência superior à média: carinho, educação, oportunidade e responsabilidade; no terceiro quadrante (inferior esquerdo) aparecem elementos como cuidado, lar, animal, necessidade, doação, esterilidade. Tais elementos periféricos objetificam e tornam pragmáticas as normas e valores presentes no núcleo da RS (ABRIC, 2003).

Tabela 2. Evocações a partir do termo indutor "adoção" para estudantes de direito.

\begin{tabular}{|c|c|c|c|c|c|c|}
\hline & \multicolumn{3}{|c|}{$\mathrm{OME}<3$} & \multicolumn{3}{|c|}{$\mathrm{OME}>=3$} \\
\hline & Elemento & $F$ & $O M E$ & Elemento & $f$ & $O M E$ \\
\hline \multirow{7}{*}{$f>9$} & Amor* & 55 & 2,87 & Carinho & 32 & 3,06 \\
\hline & Família* & 39 & 2,59 & Educação & 16 & 3,93 \\
\hline & Criança & 24 & 1,91 & Oportunidade & 14 & 3,28 \\
\hline & Afeto* & 13 & 2,76 & \multirow[t]{4}{*}{ Responsabilidade* } & \multirow[t]{4}{*}{13} & \multirow[t]{4}{*}{3,15} \\
\hline & Abandono & 12 & 1,41 & & & \\
\hline & Solidariedade & 10 & 2,1 & & & \\
\hline & Filhos & 9 & 2,33 & & & \\
\hline \multirow{13}{*}{$f<9$} & Cuidado & 8 & 2,875 & Dedicação & 8 & 3,0 \\
\hline & Lar & 7 & 2,714 & Pobreza & 7 & 3,42 \\
\hline & Animal & 5 & 2,0 & Carência & 6 & 3,83 \\
\hline & Necessidade & 5 & 2,400 & Dificuldade & 6 & 3,5 \\
\hline & Doação & 4 & 2,750 & Ajuda & 5 & 3,0 \\
\hline & Esterilidade & 4 & 2,750 & Orfanato & 5 & 3,0 \\
\hline & & & & Respeito & 5 & 3,40 \\
\hline & & & & Alegria & 4 & 4,0 \\
\hline & & & & Coragem & 4 & 3,00 \\
\hline & & & & Esperança & 4 & 4,00 \\
\hline & & & & Fraternidade & 4 & 4,75 \\
\hline & & & & Mãe & 4 & 3,5 \\
\hline & & & & Solidão & 4 & 3,75 \\
\hline
\end{tabular}

* Elementos com centralidade confirmada após a escolha das duas palavras mais importantes.

Por fim, a periferia longínqua, que se encontra no quarto quadrante (inferior direito) diz respeito às representações individuais ou de subgrupos, aspectos menos compartilhados da RS, envolvendo alguns elementos como: pobreza, carência, ajuda, orfanato, fraternidade.

O estudo da conexidade dos elementos para os estudantes de direito permite visualizar a organização da representação, cujo resultado é ilustrado na árvore máxima. 
Resultaram de 21 categorias, de modo que 16 delas (cujo número de coocorrências foi superior a 5) estão representadas na árvore (Figura 2).

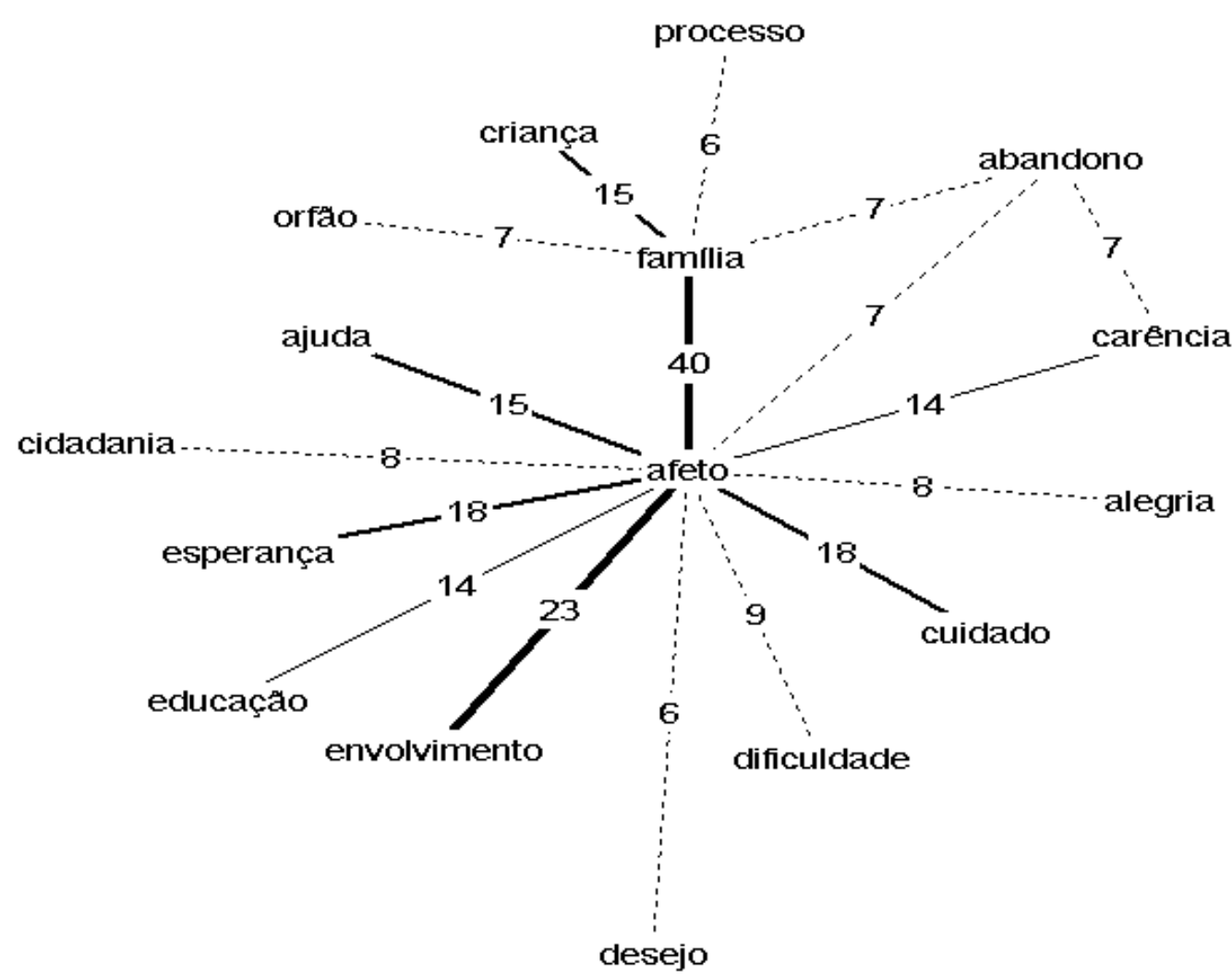

Figura 2. Árvore direito - clique 6

Verifica-se maior ligação entre os elementos afeto e família tendo maior número de coocorrências entre eles, que podem ser considerados elementos centrais, organizadores da representação (ABRIC, 2003). Também há forte ligação entre afeto e envolvimento. A categoria afeto apresenta-se como central e organiza as categorias família, envolvimento, cuidado, esperança, ajuda, educação, carência, dificuldade, alegria, cidadania, desejo e abandono. A categoria família está ligada às categorias criança, abandono, órfão e processo judicial. Ainda é possível perceber ligação, com menor frequência, entre as categorias abandono, afeto, família e carência.

RPI Revista de Pesquisa Interdisciplinar, Cajazeiras, v. 2, n. 2, 172-191, jun/dez. de 2017. 


\section{Crenças, atitudes e comportamentos relativos à adoção dos estudantes de psicologia e direito}

Para melhor compreendermos as RS dos participantes e as diferenças entre os grupos, mostra-se relevante observar algumas variáveis no que se refere à caracterização desses estudantes em relação ao fenômeno da adoção. Na Tabela 3 apresentam-se algumas de suas tendências, atitudes e proximidade quanto à adoção, o que pode auxiliar a compreender as sutis diferenças nas RS entre os grupos.

Tabela 3. Análise comparativa das questões fechadas do questionário.

\begin{tabular}{|c|c|c|c|}
\hline \multirow[t]{2}{*}{ Questões } & \multicolumn{2}{|c|}{ Curso } & \multirow[b]{2}{*}{ Todos } \\
\hline & Psicologia & Direito & \\
\hline \multicolumn{4}{|c|}{$\begin{array}{l}\text { Caso não pudesse ter filhos biológicos, você adotaria uma } \\
\text { criança ou adolescente que mora em uma instituição ou } \\
\text { abrigo? }\end{array}$} \\
\hline Adotaria & $76 \%$ & $35 \%$ & $55,5 \%$ \\
\hline Não adotaria & $4 \%$ & $15 \%$ & $9,5 \%$ \\
\hline Talvez adotaria & $20 \%$ & $50 \%$ & $35 \%$ \\
\hline \multicolumn{4}{|c|}{$\begin{array}{l}\text { Tendo filhos biológicos você adotaria uma criança ou } \\
\text { adolescente que mora em uma instituição ou abrigo? }\end{array}$} \\
\hline Adotaria & $14 \%$ & $9 \%$ & $11,5 \%$ \\
\hline Não adotaria & $12 \%$ & $28 \%$ & $20 \%$ \\
\hline Talvez adotaria & $74 \%$ & $63 \%$ & $68,5 \%$ \\
\hline \multicolumn{4}{|c|}{$\begin{array}{l}\text { Caso você entrasse na fila para a adoção, teria preferência } \\
\text { por adotar crianças com idade? }\end{array}$} \\
\hline Criança de 0 a 2 anos & $52 \%$ & $56 \%$ & $54 \%$ \\
\hline Criança de 2 a 6 anos & $19 \%$ & $13 \%$ & $16 \%$ \\
\hline Criança de 7 a 12 anos & $1 \%$ & $3 \%$ & $2 \%$ \\
\hline Adolescente & $1 \%$ & $0 \%$ & $0,5 \%$ \\
\hline Não teria preferência por idade & $19 \%$ & $17 \%$ & $18 \%$ \\
\hline Não adotariam & $6 \%$ & $11 \%$ & $8,5 \%$ \\
\hline Não respondeu & $2 \%$ & $0 \%$ & $1 \%$ \\
\hline \multicolumn{4}{|c|}{$\begin{array}{l}\text { Na sua opinião, crianças adotadas sofrem maior preconceito } \\
\text { pela sua formação familiar. }\end{array}$} \\
\hline Certamente & $16 \%$ & $18 \%$ & $17 \%$ \\
\hline Talvez & $46 \%$ & $48 \%$ & $47 \%$ \\
\hline Nunca & $38 \%$ & $34 \%$ & $36 \%$ \\
\hline
\end{tabular}




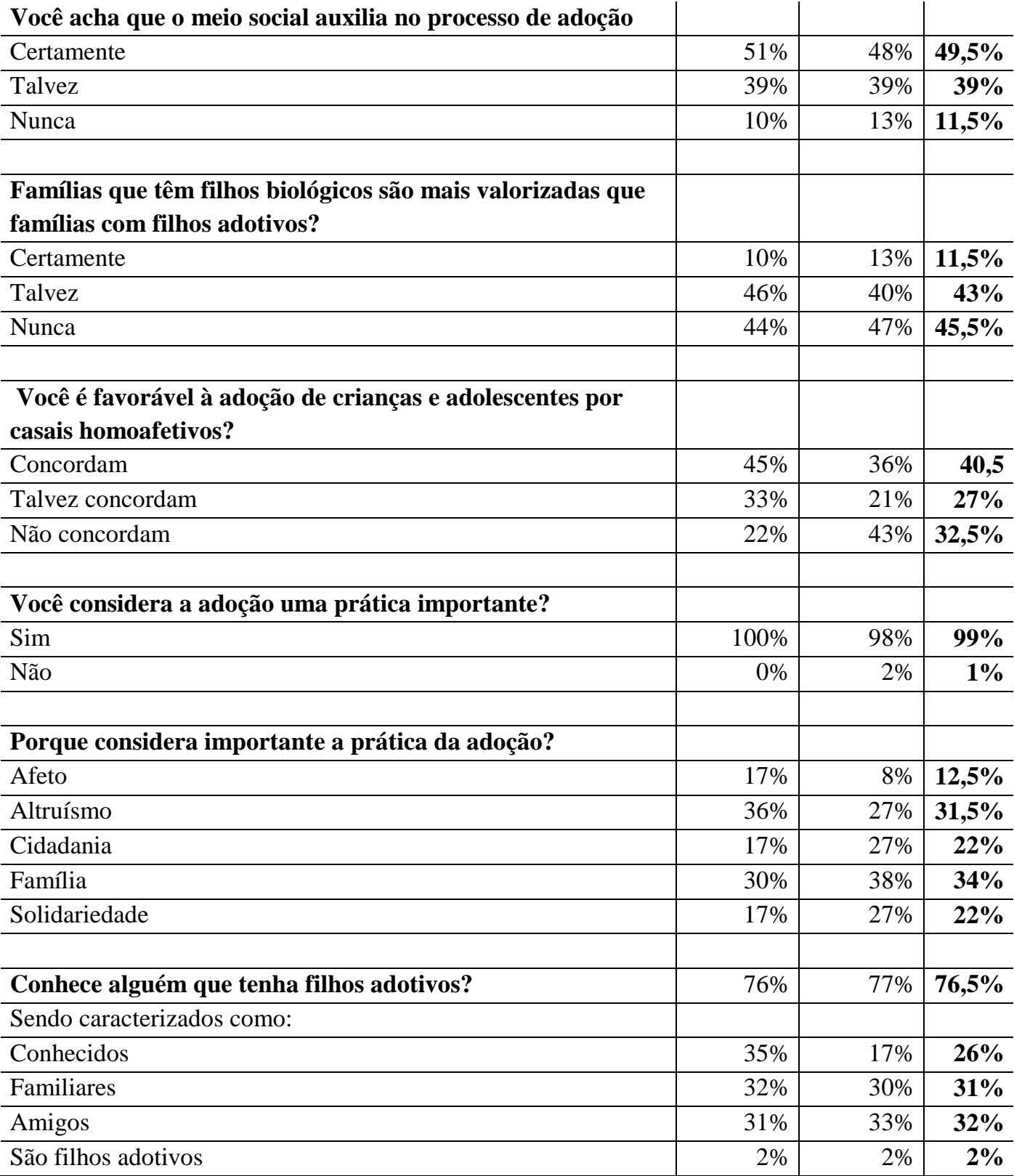

Verificou-se que os estudantes de psicologia expressam uma atitude mais favorável em relação à adoção. Todavia, essa favorabilidade é maior quando se coloca a impossibilidade de gerar filhos biológicos. A preferência de idades para adoção mostrou uma preferências pela adoção de bebês e crianças pequenas. Se por um lado, $18 \%$ dos participantes mencionam que não teriam preferência de idade, a preferência por adolescentes é quase que inexistente.

Embora não seja unânime, há a opinião de que crianças e adolescentes adotivos sofrem preconceito pela sua formação familiar; e em grande maioria, acreditam que o meio social auxilia no processo de adoção. Não há uma crença saliente sobre a 
desvalorização das famílias que se constituem por meio da adoção. Todavia, quando se fala em adoção por casais homoafetivos, os estudantes do curso de psicologia concordam com a prática e os estudantes de direito discordam.

Os dois grupos consideram a prática de adoção importante, sendo na categorização da importância destacou-se o altruísmo para o curso de psicologia e família para o curso de direito. A grande maioria dos estudantes afirmou conhecer pessoas com filhos adotivos, principalmente amigos e conhecidos. Ambos os cursos tinham dois participantes que se identificaram como filhos adotivos.

\section{Discussão}

A partir dos dados levantados constatou-se uma RS da adoção de crianças e adolescentes institucionalizados que é em grande parte compartilhada entre os estudantes de Psicologia e Direito. Amor, família e afeto foram confirmados como elementos centrais para ambos os grupos, revelando um núcleo central pautado na afetividade enquanto elemento estruturante da RS. Ademais, elementos como criança, abandono, filhos e solidariedade também foram bastante significativos a ambos os grupos.

Já os elementos periféricos envolvem também aspectos afetivos: carinho, abandono, compaixão, acolhimento; morais: responsabilidade e pragmáticos: educação, oportunidade, dificuldade, cuidado, esterilidade, dentre outros. Os elementos do sistema periférico também se equivalem nos dois cursos, mas o que podemos destacar diferenças sutis: os elementos animal e esterilidade foram evocados somente pelos alunos do curso de direito, e pena e caridade, evocados somente no curso de psicologia. Na periferia da RS encontram-se muitos elementos que são responsáveis pelos diferentes pontos de vista e práticas relativas à RS da adoção (RATEAU, 2004).

A análise de similitude evidenciou a categoria afeto como a organizadora de todos os demais elementos. A forte conexão entre os elementos centrais afeto e família indica que a noção de adoção é permeada pela afetividade, que é primordial para a formação das famílias, como aponta Schreiber (2001). Todavia, ainda é presente a ideia de que a adoção esteja ligada ao abandono, carência e órfãos. Considera-se que a RS, tal qual evidenciada pela árvore de similitude, carrega uma concepção um tanto 
estereotipada da adoção, dado sua extrema simplicidade e caracterização afetiva, o que ocorre comumente frente a objetos estereotípicos (TAJFEL, 1981).

Os julgamentos e opiniões que os estudantes emitiram sobre a adoção inscrevem na dinâmica de um campo social. As diferenças que se mostram entre os cursos nas crenças, julgamentos e práticas refletem algumas dimensões da RS da adoção que não haviam sido captadas por meio da técnica de evocação livre. A favorabilidade em relação à adoção aponta para a dimensão atitudinal da representação social (MOSCOVICI, 2012). Atitude esta que se mostrou mais positiva entre estudantes de Psicologia, quando comparados aos acadêmicos de Direito.

Embora haja uma favorabilidade em relação à adoção, a projeção da mesma na própria vida ainda apareceu associada à impossibilidade de conceber filhos biológicos. Esse tipo de concepção remete a noções já ultrapassadas acerca da adoção (WEBER, 2004), que vêm a ser questionada nas últimas décadas, sobretudo a partir da implementação do ECA em 1990.

Visualiza-se nas respostas dos participantes dos dois cursos, ao relatarem a preferência de idades no caso de adoção, o maior interesse por crianças com idades entre zero a dois anos, corroborando as pesquisas de Weber (2004). A autora aponta que suas pesquisas mostraram a preferência por crianças menores de dois anos e que ocorrem em grande número nos casos de adoção. Camargo (2005) aponta que o maior mito em relação à adoção é a formação do vínculo, onde pensam que amor e a aprendizagem somente ocorrem com filhos biológicos ou crianças adotadas desde bebês, também justificando a preferência por crianças menores de dois anos. Essas crenças mantém a tendência maior de adotar crianças pequenas, enquanto aquelas mais velhas e os adolescentes aguardam longo período por uma família.

Weber (2004), Hutz e Reppold (2003), apontam que os adotantes demonstram altruísmo como principal fator ao adotar, o que se confirmou na justificativa dos estudantes sobre a importância da adoção, onde foi encontrado o altruísmo como principal resposta na psicologia. Entre os acadêmicos e direito a importância da adoção em primeiro lugar vem da necessidade de construção de uma família em seguida aparece o altruísmo. No altruísmo, considera-se a importância social de fazer o bem a outras pessoas que estão desfavorecidas por não terem uma família constituída por pai e mãe, que dêem atenção, carinho, afeto e dignidade. 
Sobre a adoção por casais homoafetivos, os acadêmicos de psicologia, em sua grande maioria, relataram ser favoráveis à prática, o que não ocorreu dentre os estudantes de direito. Podemos relacionar com a pesquisa de Araújo et.al. (2007), que foi realizada com estudantes de psicologia e de direito sobre a adoção de crianças por casais homoafetivos. Nesse estudo, os acadêmicos de ambos os cursos não concordavam com a prática de adoção por casais homoafetivos. Assim, pode-se perceber que na presente pesquisa o grupo de acadêmicos de psicologia diferencia-se dos acadêmicos de direito, assim como dos dados do estudo anterior. Isso aponta para uma possível mudança em relação à favorabilidade à prática de adoção por casais homoafetivos, que começa a ser mais debatida e aceita em nossa sociedade. Weber (1999) coloca que em termos da relação com os filhos, esses casais e casais constituídos por homem e mulher são equivalentes, já que a capacidade de dar amor e afeto à criança é o mesmo. Ou seja, legalmente, psicológica e socialmente, não há necessidade de qualquer distinção no processo de adoção por casal homoafetivo.

Em pesquisa realizada com familiares que tinham filhos adotivos constatou-se que estes relataram sentir preconceito de conhecidos e familiares, apontando ainda que famílias que sofrem maior preconceito encontram maiores dificuldades na criação dos filhos (WEBER, 2004). Quanto menos informações as pessoas têm em relação à adoção, mais preconceituosas em relação a ela. Este preconceito é percebido socialmente e apareceu nas respostas dos participantes do estudo. Por isso, os pais precisam ser preparados para lidarem com a situação do preconceito, onde o papel do psicólogo torna-se essencial para o enfrentamento das diferenças e das dificuldades de pais e filhos (WEBER, 1999).

No meio social, segundo Camargo (2005), circulam mitos enraizados em relação ao processo de adoção. Para os acadêmicos de psicologia, o meio social talvez auxilie no processo de adoção, e os acadêmicos de direito demonstram a percepção de que o meio social pode sim auxiliar. Esse meio social carrega mitos e crenças que circulam nas comunicações interpessoais e na mídia por meio de RS.

Verificou-se uma RS hegemônica (VALA \& CASTRO, 2013) em relação à adoção. Houve poucas distinções entre os cursos no conteúdo evocado e diferenças em relação à favorabilidade da adoção. Embora os estudantes de direito e psicologia tenham em sua futura profissão a possibilidade de atuar junto aos processos de adoção, a 
representação evidencia certo distanciamento em relação ao tema. Verifica-se uma representação ainda idealizada, carregando estereótipos e pautada em valores de longa tradição histórica, mas que tem sido questionados nas atuações mais recentes perante a adoção. Tal constatação pode servir como indicador de que o tema ainda não seja suficientemente abordado nos cursos de graduação e que, por consequência, as ações dos profissionais seja fortemente atravessada mais por crenças e valores sociais.

\section{Conclusões}

A presente pesquisa trouxe contribuições e relação a como esses grupos de estudantes representam a adoção. A articulação da teoria das representações sociais na compreensão das dinâmicas de adoção trata-se de uma interlocução que ainda é pouco explorada e, nesse sentido, os resultados do estudo apontam para algumas reflexões.

Verificou-se que houve pouca interferência dá área de estudo nas representações que emergiram a partir do teste de evocações, de modo que podemos falar de uma RS compartilhada acerca do objeto em questão. Não podemos dizer que a adoção seja condição vivenciada igualmente pelos indivíduos de uma mesma sociedade, ou que possamos, a partir desse estudo, propor generalizações. Trata-se de um grupo bastante específico de estudantes do interior da região do sul do país. Todavia, salienta-se que eles se inserem em uma sociedade que compartilha representações que circulam por meio de recursos midiáticos e tecnológicos e que, portanto, podem ilustrar uma parte do pensamento social acerca do tema no Brasil. Fica evidente a necessidade de se abordar mais profundamente o assunto da adoção nas formações universitárias, especialmente porque os profissionais que atuam no campo da psicologia e do direito podem ser agentes de mudança no que se refere às práticas de adoção e, por consequência, também no que tange às crenças e representações sociais.

\section{Referências}

ABRIC, J. C. Abordagem estrutural das Representações Sociais: desenvolvimentos recentes. in P.H.F. Goiânia: UCG, 2003, p. 37- 57.

ARAÚJO, Ludgleydson Fernandes de; CASTANHA, Alessandra Ramos; OLIVEIRA, Josevânia da Silva Cruz de; SOUSA, Valdiléia Carvalho de. Adoção de Crianças por

RPI Revista de Pesquisa Interdisciplinar, Cajazeiras, v. 2, n. 2, 172-191, jun/dez. de 2017. 
Casais Homoafetivos: Um estudo comparativo entre universitários de direito e de psicologia. Cidade: Psicologia e Sociedade, 2007.

BARDIN, Laurence. L'analyse de contenu. Paris: PUF,1977.

BLOGOSLAWSKI, Ilson Paulo Ramos; FACHINI, Olímpio; FAVERI, Helena Justen de. Educar para a pesquisa: normas para produção de textos científicos. 3.ed. ver. Ampl. E atual. Rio do Sul: Nova Letra, 2010.

BRASIL. Lei Federal n ${ }^{\circ}$ 8.069, de 13 de julho de 1990. Dispõe sobre o Estatuto da criança e do adolescente.

CAMARGO, Mário Lázaro. Adoção tardia: representações sociais de famílias adotivas. Faculdade Ciências e Letras Assis: São Paulo, 2005.

HUTZ, Claudio Simon; REPPOLD, Caroline Tozzi. Reflexão social, controle percebido e motivações à adoção: características psicossociais das mães adotivas. Rio Grande do Sul: Estudos de Psicologia, 2003.

JODELET, Denise. Representações sociais: um domínio em expansão. 2001. In: (Org). As representações sociais. Rio de Janeiro: UERJ, 2001, p. 17-44.

MONACO, Gustavo Ferraz de Campos. Direitos da criança e adoção internacional. São Paulo: Editora Revista dos Tribunais, 2002.

MOSCOVICI, Serge. A psicanálise, sua imagem e seu público. Porto Alegre: Vozes, 2012.

On social representations. In: Forgas, J. P. Social Cognition. London: Academic press, 1981, p.181-209.

PALMONARI, A. \& CERRATO, J. Representações sociais e psicologia social. Em: A. M. O. Almeida; M. F. S. Santos \& Z. A. Trindade (Orgs.), Teoria das Representações Sociais: 50 anos (pp. 305-334). Brasília: Technopolitik, 2011.

RATEAU, Patrick. Princípios organizadores e núcleo central das representações sociais. Hipóteses empíricas. Arquivos Brasileiros de Psicologia, 2004, Vol. 56, No 1. SANTOS, Maria de Fátima de Souza; ALMEIDA, Leda Maria. Diálogos com a Teoria das Representações Sociais. Ed. Universitária da UFPE, 2005.

SCHREIBER, Elisabeth. Os direitos fundamentais da criança na violência intrafamiliar. Porto Alegre: Ricardo Lenz, 2001.

TAJFEL, H. Human Groups and Social Categories: Studies in Social Psychology. Londres: Cambridge University Press, 2001.

TRINDADE, Jorge. Manual de Psicologia Jurídica para Operadores de Direito. $4^{\mathrm{a}}$ Ed., Porto Alegre: Livraria do Advogado, 2010. 
VALA, J. Representações sociais e a psicologia social do conhecimento cotidiano. In: J. Vala \& M. B. Monteiro (Orgs.), Psicologia social. $7^{\mathrm{a}}$ ed. (pp. 457-502). Lisboa:

Calouste Gulbenkian, 2006.

VALA, J. \& CASTRO, P. Pensamento social e representações sociais. In Vala, J. \& Monteiro, M. B. (coord.), Psicologia social (569-602). Lisboa: Fundação CalousteGulbenkian, 2013.

VERGÈS, P., SCANO, S. \& JUNIQUE, C.. Ensembles de programmes permettant l'analyse des evocations. Aix en Provence : Université Aix en Provence (Manual). 2002.

VERGÈS, P., JUNIQUE, C., BARBRY, W., SCANO, S. \& ZELIGER, R.. Ensembles de programmes permettant l'analyse de similitude de questionnaires et de données numeriques. Aix en Provence : Université Aix en Provence (Manual). 2002.

WACHELKE, J. Representations and social knowledge: an integrative effort trough a normative structural perspective. New Ideas in Psychology, 30, 259-269, 2012. WACHELKE, João Fernando Rech; CAMARGO, Brigido Vizeu. Representações sociais, representações individuais e comportamento. Revista Interamericana de Psicologia, 2007, v. 41, p. 379-390.

WEBER, Lidia Natalia Dobrianskyj. Aspectos psicológicos da adoção. Curitiba: Juruá, 1999.

WEBER, Lídia Natalia Dobrianskyj. O Psicólogo e as Práticas de Adoção, 2004.

GONÇALVES, Hebe Signorini; BRANDÃO, Eduardo, Ponte. Psicologia jurídica no Brasil. 2 ed. p. 99-139, Rio de Janeiro: NAU, 2004. 